\title{
SHORT-TERM EFFICACY OF LOW-LEVEL LASER THERAPY IN PATIENTS WITH KNEE OSTEOARTHRITIS: A RANDOMIZED PLACEBO- CONTROLLED, DOUBLE-BLIND CLINICAL TRIAL
}

Vanessa Ovanessian Fukuda', Thiago Yukio Fukuda², Márcio Guimarães ${ }^{3}$, Silvia Shiwa ${ }^{3}$, Bianca Del Cor de Lima ${ }^{3}$, Rodrigo Álvaro Brandão Lopes Martins ${ }^{4}$, Raquel Aparecida Casarotto 5 , Patrícia Pereira Alfredo ${ }^{6}$, Jan Magnus Bjordal ${ }^{7}$, Patrícia Maria Moraes Barros Fucs ${ }^{8}$

\section{ABSTRACT}

Objective: This study was designed to evaluate the short-term efficacy of low-level laser therapy (LLLT) for improving pain and function in patients with knee osteoarthritis. Methods: Forty-seven patients with knee osteoarthritis (79 knees), of both genders, participated in this randomized controlled double-blind clinical trial. They were randomly allocated to two groups: laser group with 25 patients (41 knees) and placebo group with 22 patients (38 knees). LLLT was performed three times a week, totaling nine sessions, using a AsGa $904 \mathrm{~nm}$ laser with mean power of 60 $\mathrm{mW}$ and beam area of $0.5 \mathrm{~cm}^{2}$. Nine points were irradiated on the knee, with energy of $3.0 \mathrm{~J} /$ point. The placebo group was treated with the same laser device, but with a sealed probe. Evaluations using Lequesne, visual numerical scale (VNS), Timed Up and Go (TUG), goniometry and dynamometry were conducted before the treatment started and after the nine sessions of LLLT. Results: A significant improvement in pain and function was found in all the assessments applied to the laser group. On comparing the laser group with the placebo group, significant differences were found in the VNS-resting and Lequesne evaluations. Conclusion: Treatment with LLLT improves pain and function over the short term in patients with knee osteoarthritis.

Keywords - Laser Therapy, Low-Level; Osteoarthritis, Knee; Exercise Therapy

\section{INTRODUCTION}

Osteoarthritis (OA) is a chronic multifactorial disease that leads to a state of osteochondral insufficiency, in which mechanical overload is one of the main factors predisposing towards osteoarticular lesions. The current concept maintains that $\mathrm{OA}$ involves the entire joint complex, including the subchondral bone, menisci,

ligaments, periarticular muscles, capsule and synovium $^{(1,2)}$.

Many factors may be involves in the etiology of OA, such as age, female gender, genetic predisposition, morphological joint abnormalities, obesity, repetitive trauma relating to occupational tasks, post-trauma factors, mechanical stress, joint instability generated through displaced alignment,

\footnotetext{
1 - MSc in Health Sciences, School of Medical Sciences, Irmandade da Santa Casa de Misericórdia (ISCMSP), São Paulo, SP, Brazil.

2 - Associate Professor, Physiotherapy Sector, Irmandade da Santa Casa de Misericórdia (ISCMSP), São Paulo, SP, Brazil.

3 - Postgraduate Student, Physiotherapy Sector, Irmandade da Santa Casa de Misericórdia (ISCMSP), São Paulo, SP, Brazil.

4 - Associate Professor, Institute of Biomedical Sciences, University of São Paulo (USP), São Paulo, SP, Brazil.

5 - Associate Professor, Physiotherapy Sector, University of São Paulo (USP), São Paulo, SP, Brazil.

6 - Doctoral Student in Experimental Physiopathology, School of Medicine, University of São Paulo (USP), São Paulo, SP, Brazil.

7 - Titular Professor, Physiotherapy Sector, Bergen University, Norway.

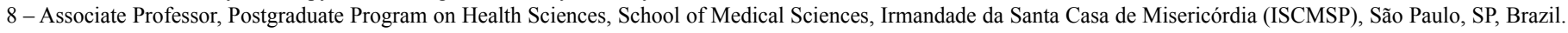
Work performed in the Physiotherapy Sector, Irmandade da Santa Casa de Misericórdia de São Paulo (ISCMSP).

Correspondence: Thiago Yukio Fukuda, Setor de Fisioterapia, Rua Dr. Cesário Mota Jr. 112, 02112-020 São Paulo, SP, Brazil; E-mail: tfukuda10@yahoo.com.br Work received for publication on September 14, 2010; accepted for publication: December 23, 2010.
}

The authors declare that there was no conflict of interest in conducting this work 
flaccidity or hypotrophy of joint stabilization elements, and metabolic and endocrine factors ${ }^{(3,4)}$.

The current therapeutic strategies aim essentially towards pain control, joint function improvement and patient reeducation to minimize the functional incapacity. The recommended treatment should follow an order that consists firstly of non-pharmacological treatment, followed by pharmacological therapy and then, if necessary, a surgical procedure ${ }^{(2,5)}$. Most international clinical guidelines advocate therapeutic exercises as fundamental for rehabilitation of patients with knee $\mathrm{OA}$, and exercises are also effective for treating chronic joint pain ${ }^{(6,7)}$.

In addition to kinesiotherapy, certain physical methods such as ultrasound, shortwave, transcutaneous electrical nerve stimulation (TENS) and low-level laser therapy (LLLT) have been used with analgesic and anti-inflammatory $\operatorname{aims}^{(8-10)}$. These methods are important because they attempt to reduce or avoid the side effects caused by medications, given that use of medications in OA cases implies an increasing risk of hospitalization due to gastrointestinal or cardiovascular disorders ${ }^{(11)}$.

LLLT consists of a monochromatic light source without any thermal effect that stimulates reparative properties in human cartilage. Moreover, it has an analgesic effect, although the mechanisms through which this occurs remain uncertain. The suggested mechanisms include: increased mitochondrial ATP and tissue oxygenation, increased levels of neurotransmitters implicated in pain modulation (such as serotonin) and anti-inflammatory effects ${ }^{(5,12)}$.

One topic that has been much discussed in the literature is the LLLT dose that should be used for treating knee OA, given that while some authors have found good results through applying LLLT, others have not. Hence, controversy surrounds its clinical efficacy and further studies become necessary ${ }^{(9,13-15)}$.

The aim of the present study was to assess the short-term efficacy of LLLT for pain alleviation and functional improvement among patients with knee OA.

\section{SAMPLE AND METHODS}

This study was a double-blind, placebo-controlled randomized clinical trial conducted in the Physiotherapy Sector of the Rehabilitation Service of Irmandade da Santa Casa de Misericórdia de São Paulo (ISCMSP), between July 2008 and February 2010. All the procedures were carried out after obtaining approval from the Research Ethics Committee (protocol no. 112/08). The trial was registered in the Latin American Clinical Trials Register (LATIN-REC) under protocol no. BRA 106.

All the patients were informed about the procedures that would be carried out, and those that agreed signed a free and informed consent statement, in accordance with the norms of National Health Board Resolution 196/96.

\section{SAMPLE}

Patients of both sexes aged between 50 and 78 years were included in the study. All of them presented knee pain and reduced functional ability over the preceding three months, and a radiographic examination showing knee OA of grade II, III or IV, according to the classification of Kellgren and Lawrence ${ }^{(16)}$ (Table 1). A total of 53 subjects participated in the first evaluation, but six were excluded because they did not fulfill one of the abovementioned criteria. Thus, 47 outpatients (79 knees) with a diagnosis of knee OA were included, comprising 34 women and 13 men. These individuals were randomly distributed into two groups: 25 patients (41 knees) in the laser group and 22 patients ( 38 knees) in the placebo group. At the start of the study, the two groups were homogenous $(p>0.05)$ in relation to age, weight, height and BMI (Table 2).

The criteria for patient exclusion consisted of presentation of any of the following: history of cancer, dementia, neurological deficits (sensory or motor), heart pacemaker, type I or decompensated diabetes, uncontrolled system arterial hypertension, or morbid obesity $(\mathrm{BMI} \geq 40)^{(4)}$. Furthermore, patients were also excluded if they had made use of antidepressants, antiinflammatory agents, steroids or tranquillizers over the last six months, or if they presented symptomatic hip OA, acute diseases or other rheumatoid or orthopedic diseases that could interfere with the results, or if they had undergone physiotherapy during the last six months. 
Table 1 - Distribution of the degree of knee osteoarthritis between the groups.

\begin{tabular}{c|c|c}
\hline $\begin{array}{c}\text { Radiographic grade } \\
\mathbf{( K L )}^{*}\end{array}$ & $\begin{array}{c}\text { Laser group } \\
\mathbf{n = 4 1}\end{array}$ & $\begin{array}{c}\text { Placebo group } \\
\mathbf{n}=\mathbf{3 8}\end{array}$ \\
\hline Grade II & $31(75.6 \%)$ & $27(71.1 \%)$ \\
\hline Grade III & $8(19.5 \%)$ & $9(23.7 \%)$ \\
\hline Grade IV & $2(4.9 \%)$ & $2(5.3 \%)$ \\
\hline
\end{tabular}

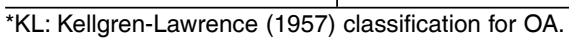
$\mathrm{p}=0.895$ (chi-square test).

Table 2 - Characteristics and demographic data (mean \pm standard deviation) of the study groups, with $p$ value.

\begin{tabular}{|c|c|c|c|}
\hline & $\begin{array}{l}\text { Laser group } \\
\qquad n=25\end{array}$ & $\begin{array}{c}\text { Placebo } \\
\text { group } \\
\mathbf{n}=\mathbf{2 2} \\
\end{array}$ & $p$ value \\
\hline Age (years) & $63.0 \pm 9.0$ & $63.0 \pm 8.0$ & $0.870^{\mathrm{a}}$ \\
\hline Weight (kg) & $74.8 \pm 13.1$ & $74.7 \pm 12.2$ & $0.980^{\mathrm{a}}$ \\
\hline Height (cm) & $1.58 \pm 0.08$ & $1.61 \pm 0.07$ & $0.105^{a}$ \\
\hline BMI (kg/m2) & $30.0 \pm 3.5$ & $28.7 \pm 4.1$ & $0.242^{\mathrm{a}}$ \\
\hline \multicolumn{4}{|l|}{ Gender } \\
\hline Female & $20(80 \%)$ & $14(64 \%)$ & \multirow{2}{*}{$0.211^{b}$} \\
\hline Male & $5(20 \%)$ & $8(36 \%)$ & \\
\hline \multicolumn{4}{|l|}{ Side affected } \\
\hline Right & 7 (28\%) & $5(23 \%)$ & \\
\hline Left & $2(8 \%)$ & $1(5 \%)$ & $0.788^{b}$ \\
\hline Bilateral & $16(64 \%)$ & $16(73 \%)$ & \\
\hline
\end{tabular}

a: Student's $t$ test ${ }^{\text {b: }}$ chi-square test.

\section{METHODS}

This clinical trial was conducted by means of random distribution of the subjects into two specific groups (laser and placebo). This distribution was made by a secretary who was not involved in the treatment or in the evaluation, through a draw of sealed opaque envelopes containing the group to which each patient would be allocated. The envelope was taken directly to the therapist, without the patient having access to the result.

The patients in both groups underwent three weeks of treatment with LLLT, consisting of three sessions per week and totaling nine sessions. The equipment used was an Irradia class 3B laser that had been previously measured and calibrated, The pen used was of AsGa type, with a wavelength of $904 \mathrm{~nm}$ in the infrared spectrum, at a frequency of $700 \mathrm{~Hz}$, with mean power of $60 \mathrm{~mW}$ and peak power of $20 \mathrm{~W} ; 50$ seconds per point and beam area of 0.5 $\mathrm{cm} 2$. This equipment was produced with two identical pens, of which one was active (laser) and the other was sealed (placebo). These were labeled A and B by the project secretary, and only this person knew the true identifications of the pens. This information was recorded and kept safe in a closed envelope until all the data had been gathered. The pens labeled with the letter A were the laser group and the pens labeled B were the placebo group.

Because this type of laser presents invisible radiation, the therapist was unaware of which group the patient belonged to (blind therapy).

The LLLT was administered in accordance with the recommendations of the World Association of Laser Therapy ${ }^{(17)}$, with regard to choosing the treatment dose per point in the knee OA. Five points were irradiated with LLLT on the medial face of the knee and four points on the lateral face, in the region of the joint capsule and synovial membrane, with energy of $3.0 \mathrm{~J}$ per point and total energy of $27.0 \mathrm{~J}$ per session.

\section{EVALUATION}

The diagram in Figure 1 shows that the patients in this study underwent evaluations at two different times: one before starting the treatment (initial evaluation) and the other at the end of the three weeks of laser application (post-laser evaluation).

At each evaluation time, the patients were examined in relation to pain and function using the following assessments and scales: Timed Up and Go (TUG) test $^{(18)}$, goniometry on knee flexion ${ }^{(19)}$, dynamometry

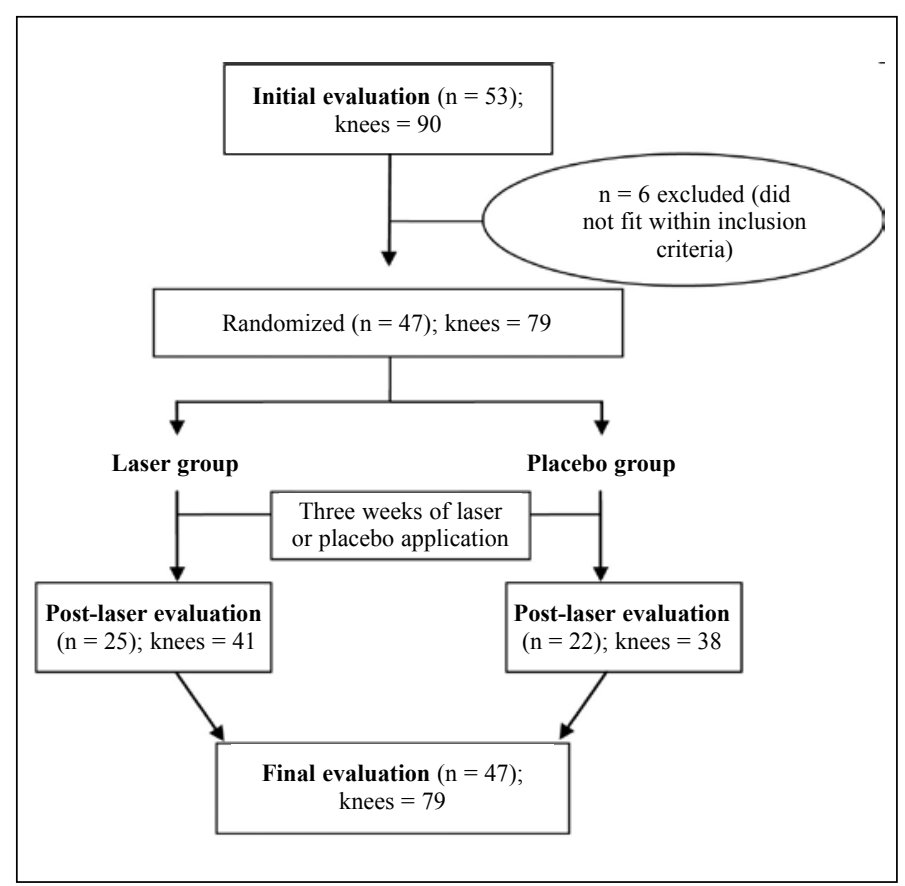

Figure 1 - Flow diagram for study design. 
on the quadriceps muscle at $60^{\circ}$ of knee flexion ${ }^{(20)}$, 11-point visual numerical pain scale (VNPS) ${ }^{(21)}$ and Lequesne algofunctional questionnaire ${ }^{(22)}$.

The VNPS consisted of a ruler divided into 11 equal parts numbered from 0 to 10 , in which 0 corresponded to "no pain" and 10 corresponded to the "worst pain imaginable". This scale was used to evaluate pain during activities of daily living (ADLs) and at rest, in which patients indicated the number corresponding to the intensity of their pain ${ }^{(21,23)}$.

The Lequesne algofunctional questionnaire for knee $\mathrm{OA}$ is an evaluation tool composed of 10 questions on pain, discomfort and function. The sum of the scores is classified as little effect ( 1 to 4 points), moderate effect (5 to 7 points), severe effect ( 8 to 10 points), very severe effect (11 to 13 points) and extremely severe effect (greater than or equal to 14 points) $)^{(24,25)}$.

The TUG test assesses physical mobility, balance and the risk of falling among elderly people. The time that patients take to get up from a chair, cross a distance of three meters, come back and sit down on the same chair is measured. Elderly people who complete this in 10 to 20 seconds are at low risk of falling; 20 to 30 seconds, moderate risk; and more than 30 seconds, high risk $^{(18)}$

The assessment on quadriceps muscle strength using a manual dynamometer (Lafayette ${ }^{\circledR}$ Instrument Co.) was done using the maximum voluntary isometric contraction (MVIC) of the quadriceps at $60^{\circ}$ of lower leg flexion. The patients remained seated on the edge of the bed, with the thigh stabilized, and extension exertion was made. The dynamometer was on the distal portion of the lower leg. Three measurements were made, and the average between them was recorded. The data were then normalized in relation to each patient's weight. The following formula was used for this normalization ${ }^{(20)}$ :

$$
\text { (Kg force / Kg weight) x } 100
$$

This manual dynamometer has excellent reproducibility for evaluating quadriceps muscle strength $^{(26)}$. This technique has been regarded as being equivalent to using isokinetic dynamometry for this muscle group. It is also an inexpensive technique and is used clinically by rehabilitation specialists ${ }^{(27)}$. Prior to the force analyses, a pilot study was conducted on 10 volunteers who were evaluated bilaterally twice, with a one-week interval between assessments. According to the intraclass correlation coefficient, the results obtained showed good reproducibility (ICC $=0.85$ ).

All these evaluations on pain, function, muscle strength and radiographic classification of the knee OA were made by a single blinded examiner, i.e. a professional who was unaware of the group that the patient belonged to.

\section{DATA ANALYSIS}

The qualitative variables were presented in terms of absolute and relative frequencies, and the quantitative variables were presented using summary measurements and boxplot graphs. To analyze the demographic data, functional tests and pain levels at the initial evaluation, Student's I test and the chisquare test were used with the aim of ascertaining whether the sample presented homogeneity.

For analyses within the groups, comparing the different evaluation times, the $t$ test for paired data was used. For analyses between groups, Student's $t$ test for parametric data or the Mann-Whitney test for non-parametric data was used. The significance level used in this study was $5 \%$, i.e. $\mathrm{p}<0.05$ denoted a significant difference. The statistical software used for these data analyses was SPSS (Statistical Package for the Social Sciences), version 13.0.

\section{RESULTS}

The initial evaluations on pain and functional ability showed that the two groups were homogenous at the start of the treatment (Table 3).

The data relating the initial and post-laser evaluations are shown in Table 4.

Intragroup analysis on the visual numerical scale data relating to activities of daily living (VNPS for ADLs) showed that in the laser group, the postlaser pain was significantly lower than in the initial evaluation $(p<0.001)$. In the same analysis, the placebo group did not show any significant improvement in pain in the post-laser evaluation, in relation to the initial evaluation $(p<0.06)$. No significant differences were found in the comparisons between groups, for the post-laser evaluations ( $p>0.10)$.

In the intragroup VNPS analysis at rest, both groups (laser and placebo) improved significantly in the 
post-laser evaluations $(\mathrm{p}<0.001)$, in comparison with the initial evaluation. However, in the comparative analysis between the groups, the laser group presented a significant improvement in relation to the placebo group $(\mathrm{p}<0.05)$ in the post-laser evaluation (Table 4$)$.

In intragroup analysis on the results from the Lequesne algofunctional questionnaire, the laser group showed a significant improvement in the

Table 3 - Summary measurements followed by $p$ value for the initial evaluations, to ascertain whether the sample was homogenous.

\begin{tabular}{|c|c|c|c|c|}
\hline Evaluation & Group & Mean ( \pm SD) & Median & p \\
\hline \multirow{2}{*}{ VNPS for ADLs } & Laser & $6.1( \pm 2.6)$ & 6 & \multirow{2}{*}{$0.801^{\circ}$} \\
\hline & Placebo & $6.2( \pm 2.3)$ & 7 & \\
\hline \multirow{2}{*}{ VNPS at rest } & Laser & $4.1( \pm 3.1)$ & 4 & \multirow{2}{*}{$0.455^{\circ}$} \\
\hline & Placebo & $4.6( \pm 2.9)$ & 5 & \\
\hline \multirow{2}{*}{ Lequesne } & Laser & $11( \pm 4.4)$ & 11 & \multirow{2}{*}{$0.706^{\circ}$} \\
\hline & Placebo & $10.7( \pm 3.2)$ & 11 & \\
\hline \multirow{2}{*}{ TUG } & Laser & $9.2( \pm 3.4)$ & 9 & \multirow{2}{*}{$0.958^{\circ}$} \\
\hline & Placebo & $9.3( \pm 2.8)$ & 8.9 & \\
\hline \multirow{2}{*}{$\begin{array}{l}\text { Goniometry } \\
\text { (Flexion) }\end{array}$} & Laser & $117.5( \pm 7.1)$ & 118 & \multirow{2}{*}{$0.056^{\circ}$} \\
\hline & Placebo & $121.4( \pm 10.7)$ & 123 & \\
\hline \multirow{2}{*}{$\begin{array}{c}\text { Dynamometry } \\
\left(60^{\circ}\right)\end{array}$} & Laser & $23.7( \pm 13.0)$ & 23.7 & \multirow{2}{*}{$0.349^{\circ}$} \\
\hline & Placebo & $21.3( \pm 8.9)$ & 21.7 & \\
\hline
\end{tabular}

a TStudent's t test.

Table 4 - Summary measurements and confidence intervals for mean results from VNPS, Lequesne, TUG, range of motion and dynamometry pain and functional scales.

\begin{tabular}{|c|c|c|}
\hline & $\begin{array}{l}\text { Initial mean evaluation } \\
\quad( \pm \text { SD) }(95 \% \mathrm{Cl})\end{array}$ & $\begin{array}{c}\text { Post-laser mean evaluation } \\
\quad( \pm \mathrm{SD})(95 \% \mathrm{Cl})\end{array}$ \\
\hline \multicolumn{3}{|c|}{ VNPS (for ADLs) } \\
\hline Laser & $6.1 \pm(2.6)(5.3-6.9)$ & $4.4 \pm(2.9)(4.0-4.9)$ \\
\hline Placebo & $6.2 \pm(2.3)(5.8-6.6)$ & $5.3 \pm(2.8) \quad(4.4-6.2)$ \\
\hline \multicolumn{3}{|c|}{ VNPS (at rest) } \\
\hline Laser & $4.1 \pm(3.1)(3.1-5.1)$ & $1.9 \pm(2.6)(1.1-2.8)$ \\
\hline Placebo & $4.6 \pm(2.9)(3.7-5.6)$ & $3.0 \pm(2.7)(2.1-3.9)$ \\
\hline \multicolumn{3}{|c|}{ Lequesne } \\
\hline Laser & $11.0 \pm(4.4)(9.6-12.4)$ & $7.8 \pm(4.7)(6.4-9.2)$ \\
\hline Placebo & $10.7 \pm(3.2)(9.7-11.7)$ & $9.7 \pm(3.9)(8.5-10.9)$ \\
\hline \multicolumn{3}{|c|}{ TUG } \\
\hline Laser & $9.2 \pm(3.4)(7.8-10.6)$ & $8.0 \pm(1.9)(7.2-8.7)$ \\
\hline Placebo & $9.3 \pm(2.8)(8.0-10.5)$ & $8.2 \pm(2.1)(7.3-9.1)$ \\
\hline \multicolumn{3}{|c|}{ Goniometry (Flexion) } \\
\hline Laser & $117.5 \pm(7.1)(115.2-119.7)$ & $122.7 \pm(10.0)(119.5-125.9)$ \\
\hline Placebo & $121.4 \pm(10.7)(117.9-124.9)$ & $124.2 \pm(10.8)(120.7-127.7)$ \\
\hline \multicolumn{3}{|c|}{ Isokinetic evaluation $\left(60^{\circ}\right)$} \\
\hline Laser & $23.7 \pm(13.0)(19.6-27.8)$ & $25.9 \pm(12.3)(22.0-29.8)$ \\
\hline Placebo & $21.3 \pm(8.9)(18.4-24.2)$ & $27.0 \pm(9.0)(24.0-30.0)$ \\
\hline
\end{tabular}

post-laser evaluation in relation to the initial evaluation $(\mathrm{p}<0.001)$. In the same analysis, the placebo group did not show any significant improvement in the post-laser evaluation in relation to the initial evaluation $(p<0.10)$. Thus, in the comparison between groups, the laser group presented a significant improvement in relation to the placebo group ( $\mathrm{p}<$ 0.05 ) in the post-laser evaluation (Table 4).

In the goniometry evaluation on knee flexion in the intragroup analysis, the laser group showed a significant improvement in the post-laser evaluation in relation to the initial evaluation $(\mathrm{p}<0.001)$. In the same analysis, the placebo group did not show any significant improvement in the post-laser evaluation $(p<0.06)$. In relation to the comparative analysis between groups, there was no difference in the post-laser evaluations $(\mathrm{p}>0.50)$ (Table 4).

Intragroup analysis on the dynamometry data showed that both groups had significant improvements in the post-laser analysis, in relation to the initial evaluation $(p<0.001)$. In the comparative analysis between the groups, there was no difference in the post-laser evaluations $(\mathrm{p}>0.60)($ Table 4$)$.

Intragroup analysis on the TUG test in the laser group showed that there was a significant improvement in the post-laser evaluation, in relation to the initial evaluation $(\mathrm{p}<0.002)$. An improvement was also found in the placebo group, in the post-laser evaluation $(p>0.60)$ (Table 4).

\section{DISCUSSION}

This was a placebo-controlled double-blind clinical trial with random distribution that had the aim of evaluating the effect of LLLT for pain alleviation and functional improvement among patients with knee OA. The results obtained showed that application of infrared AsGa laser with final energy of $3.0 \mathrm{~J}$ per point could be an important auxiliary tool for treating this osteoarticular abnormality. Since this is a relatively common disease among adults and elderly people, especially because of increased life expectancy among the population, many studies have been conducted on OA, with the aim of finding effective resources for pain relief and improved quality of life for these patients $^{(3,28)}$. It was decided to study this population because of the high demand for treatment of impaired knee joints. LLLT is a widely used resource in clinics, 
with well-established therapeutic results ${ }^{(29)}$, but in relation specifically to knee $\mathrm{OA}$, the results remain controversial $^{(9,14)}$.

Low-level AsGa laser in the infrared spectrum was used because this has deeper penetration than visible red light does ${ }^{(30,31)}$. Thus, it can reach all the periarticular structures involved in OA and probably acts as an analgesic, an anti-inflammatory agent in relation to reactive synovitis and a reparative agent for cartilaginous tissue ${ }^{(32-35)}$.

The pain and function assessments were conducted using validated questionnaires that have been widely used in the literature, in Brazil and worldwide, such as the Lequesne algofunctional questionnaire, visual numerical pain scale (VNPS), knee flexion goniometry, quadriceps muscle strength dynamometry at 60 degrees of knee flexion and TUG functional test. Knee extension goniometry was also performed, but it was decided not to add this to the study because some patients presented an extension deficit due to bone blockage, which is a consequence of the natural evolution of the disease, thus making it impossible to compare the likely gains in range of motion after using LLLT and exercises. It was decided to study muscle strength only using the quadriceps because this muscle group is the one most affected by arthrogenic inhibition and has an important dynamic stabilization function in relation to the knee joint ${ }^{(36,37)}$.

Several progressive and degenerative diseases have been effectively treated by means of LLLT ${ }^{(12,38,39)}$, but there is controversy regarding the results from studies analyzing pain and function among patients with knee OA, mainly because of the variations in the methods used. In the present clinical trial, care was taken to follow the WALT recommendations ${ }^{(40)}$ regarding how to conduct a clinical trial with LLLT, and care was taken to report all the parameters used in the study. Because some important data was not reported in some studies, such as wavelength, treatment duration, final energy, application method, mean power, duration of application and beam area, meta-analyses have been unable to reach conclusions regarding the ideal parameters for LLLT ${ }^{(38)}$.

In the present study, pain relief and functional improvement were achieved in the laser group after nine LLLT sessions using an AsGa laser with wavelength of $904 \mathrm{~nm}$, frequency of $700 \mathrm{~Hz}$, mean power of $60 \mathrm{~mW}$, peak power of $20 \mathrm{~W}$, beam area of
$0.5 \mathrm{~cm} 2$, application time per point of 50 seconds, dose of $3.0 \mathrm{~J}$ and energy density of $6.0 \mathrm{~J} / \mathrm{cm} 2$ per point. In comparison with the placebo group, the laser group showed significant differences in the VNPS evaluation at rest and the Lequesne algofunctional questionnaire. The present study is corroborated by a double-blind randomized controlled clinical trial by Gur et al ${ }^{(13)}$, in which 90 patients were distributed into three groups: group I, with $3.0 \mathrm{~J}$; group II, with 2.0 $\mathrm{J}$; and a placebo group. Their study used laser of 904 $\mathrm{nm}$, beam area of $1 \mathrm{~cm} 2$ and mean power of 10 and $11.2 \mathrm{~mW}$ for five and three minutes of application. In association with this, isometric contraction exercises were performed on the quadriceps, in 10 sessions over two weeks, from which significant improvements in pain, function and quality of life were found among patients with knee OA. With regard to dose, the group with $3.0 \mathrm{~J}$ showed a tendency to be better than the group with $2.0 \mathrm{~J}$, but without any statistical difference.

As mentioned earlier, the ideal energy dose has still not been well established, although it has been observed that doses greater than $3.0 \mathrm{~J}$ seem to present better results. In clinical trials conducted in accordance with the WALT recommendations, Hegedus et al ${ }^{(9)}$ and Montes-Molina et al ${ }^{(15)}$ used laser of $830 \mathrm{~nm}$ with mean power of 50 and $100 \mathrm{~mW}$, respectively, and a dose of $6.0 \mathrm{~J}$ per point, and obtained effective results regarding pain relief and improvement of microcirculation in the irradiated area. Their data are concordant with the findings of the present study, which found positive effects in the laser group with a dose of $3.0 \mathrm{~J}$. Another clinical trial, albeit not doubleblind, used a dose of $3.0 \mathrm{~J}$ in one group and $1.5 \mathrm{~J}$ in the other, with an AsGaAl laser of $830 \mathrm{~nm}$ and mean power of $50 \mathrm{~mW}$, but did not find any significant improvement in pain. This may be related to the area of laser application: directly at the painful points and not around the joint capsule or synovial membrane ${ }^{(14)}$.

Another two clinical trials on LLLT also did not find good results. One of these was the study by Dominguez-Carrilho ${ }^{(10)}$, and that result was probably due to the low energy density used $(0.5 \mathrm{~J} /$ $\mathrm{cm} 2$ ). Moreover, because of lack of data, it was not possible to calculate the final energy distributed to the tissue. In the study by Bülow et al ${ }^{(41)}$, a laser of $830 \mathrm{~nm}$ and mean power of $25 \mathrm{~mW}$ was used, with doses of 1.5 to $4.5 \mathrm{~J}$. In total, there were 15 minutes of irradiation per session, thus giving a total dose 
per treatment of $22.5 \mathrm{~J}$, which was distributed as an average of $2.5 \mathrm{~J}$ per point. Thus, these non-significant LLLT results can be explained by the dose of less than $3.0 \mathrm{~J}$ and also by the application at pain points and not directly to the periarticular soft tissues. Application of laser to the region of the joint capsule and synovium has been advised by some researchers, like in the systematic review by Bjordal et $\mathrm{al}^{(29)}$, which showed that application in this region significantly reduced the pain and improved the overall state of health of patients with chronic joint pain. WALT ${ }^{(17)}$ also advised this form of application. Based on this information, the applications in the present study had the aim of diminishing or controlling reactive synovitis in knees affected by OA.

The exact effects from using LLLT remain uncertain. Some explanations can be found in different experimental studies, which suggest that LLLT has an anti-inflammatory, analgesic and reparative effect. In a meta-analysis, Brosseau et al ${ }^{(38)}$ stated that the reduction in pain through using LLLT might be due to mechanisms such as physiological effects mediated by photochemical actions at cellular level in animal or human tissue, and through increased levels of the neurotransmitters implicated in pain modulation, such as serotonin. Some researchers have also concluded that LLLT has an effect on joint cartilage regeneration, achieved through proliferation of chondrocytes and synthesis and secretion of extracellular matrix ${ }^{(32,34)}$. Through LLLT, there is an improvement in local circulation, which leads to reduced edema and improved

\section{REFERENCES}

1. Fuller R,Hirose-Pastor EM. Osteoartrose. In: Yoshinari, Bonfá ESDO. Reumatologia para o clínico. São Paulo: Roca; 2000. p. 139-46.

2. Hunter DJ, Felson DT. Clinical review: Osteoarthritis. British Medical Journal [periódico online] 2006; [citado 17 abril 2008]; 332: 639-642. Disponível em: http://bmj.com/cgi/content/full/332/7542/639

3. Bjordal JM, Johnson MI, Martins LR, Bogen B, Chow R, Ljunggren AE. Short-term efficacy of physical interventions in osteoarthritic knee pain: A systematic review and meta-analysis of randomized placebo-controlled trials. BMC Musculoskeletal Disorders. [periódico online] 2007; [citado 5 maio 2008]; 8: 51-64. Disponível em: http://www.biomedcentral.com/14712474/8/51

4. Blagojevic M, Jinks C, Jeffery A, Jordan KP. Risk factors for onset of osteoarthritis of the knee in older adults: a systematic review and meta-analysis. Osteoarthritis Cartilage. 2010;18(1):24-33.

5. Shen X, Zhao L, Ding G, Tan M, Gao J, Wang L, et al. Effect of combined laser acupuncture on knee osteoarthritis: a pilot study. Lasers Med Sci. 2009;24(2):129-36.

6. Thomas SG, Pagura SM, Kennedy D. Physical activity and its relationship to physical performance in patients with end stage knee osteoarthritis. J Orthop Sports Phys Ther. 2003;33(12):745-54.

7. Fransen M, McConnell S. Land-based exercise for osteoarthritis of tissue oxygenation, which consequently may result in pain alleviation $^{(9)}$.

In the literature, it has been well established that physical exercise is the most important resource for conservative treatment of knee OA, since it achieves pain reduction and functional improvement among these patients ${ }^{(7,42)}$. Thus, it can be seen that some studies have presented good results through combining LLLT with exercises, especially for quadriceps strengthening, from the outset of the treatment ${ }^{(13,15)}$. The exercises can be done under supervision by a physiotherapist individually or in groups, or through a home-based program. The important point, according to the meta-analysis by Fransen and McConnell( ${ }^{(7)}$, is the frequency, which should be greater than 12 sessions of exercises and guidance. This approach is included in approximately $98 \%$ of physiotherapists' management of patients with knee $\mathrm{OA}^{(43)}$.

The physical resource used in the present study may be an important adjunct tool, especially if associated with exercises for conservative treatment of knee OA, and especially because it does not present the adverse effects usually encountered with anti-inflammatory and analgesic medications.

\section{CONCLUSIONS}

After assessment of the data obtained in this study, we can conclude that the treatment with low-level laser alleviated pain and improved functional ability over the short term, among patients with knee OA.

the knee: a metaanalysis of randomized controlled trials. J Rheumatol. 2009;36(6):1109-17.

8. Ovanessian, V, Cazarini Junior C, Cunha RA, Carvalho NAA, Fukuda TY. Use of different doses of pulsed short waves in the treatment of patients with osteoarthritis of the knee. Rev Ciências Med (PUCCAMP). 2008:17:149-55.

9. Hegedus B, Viharos L, Gervain M, Galfi M. The effect of low-level laser in knee osteoarthritis: A Double-blind, randomized, placebo-controlled trial. Photomed Laser Surg. 2009;27(4):577-84.

10. Dominguez-Carrilo LG. Comparación de la electroestimulación transcutánea vs laser de bajo nivel en la analgesia de pacientes con gonartrosis. Cir \& Cir. 2001;69(1):13-7.

11. Johnsen SP, Larsson H, Tarrone RE, McLaughlin JK, Friis S, Sorensen $\mathrm{HT}$ et al. Risk of hospitalization for myocardial infarction among users of refecoxib, celecoxib, and other NSAIDs: a population-based case-control study. Arch Intern Med. 2005;165(9):978-84.

12. Brosseau L, Wells G, Marchand S, Gaboury I, Stokes B, Morin M,et al. Randomized controlled trial on low level laser therapy (LLLT)in the treatment of osteoarthritis (OA) of the hand. Lasers Surg Med. 2005;36(3):210-9.

13. Gur A, Cosut A, Sarac AJ, Cevik R, Nas K, Uyar A. Efficacy of different therapy regimes of low-power laser in painful osteoarthritis of the knee: a double-blind and randomized-controlled trial. Lasers Surg Med. 2003;33(5):330-8. 
14. Tascioglu F, Armagan O, Tabak Y, Corapci I, Oner C. Low power laser treatment in patients with knee osteoarthritis. Swiss Med Wkly. 2004;134(17-18):254-8.

15. Montes-Molina R, Madroñero-Agreda MA, Romojaro-Rodríguez AB, GallegoMendez V, Prados-Cabiedas C, Marques-Lucas C, et al. Efficacy of interferential low-level laser therapy using two independent sources in the treatment of knee pain. Photomed Laser Surg. 2009;27(3):467-71.

16. Kellgren JH, Lawrence JS. Radiological assessment of osteo-arthrosis. Ann Rheum Dis. 1957;16(4):494-502.

17. World Association of Laser Therapy (WALT). Laser dosage table for musculoskeletal disorders using $904 \mathrm{~nm}$ pulse laser. World Association Laser Therapy; 2005. Available from: http://www.walt.nu/images/stories/files/dosagetable-904nm.v1.1.pdf (15 mar. 2008).

18. Podsiadlo D, Richardson S. The timed "Up \& Go": a test of basic functional mobility for frail elderly persons. J Am Geriatr Soc. 1991;39(2):142-8.

19. Hoppenfeld S. Exame do joelho. In: Hoppenfeld S. Propedêutica ortopédica: coluna e extremidades. São Paulo: Atheneu; 2002. p. 196-98.

20. Piva SR, Goodnite EA, Childs JD. Strength around the hip and flexibility of soft tissues in individuals with and without patellofemoral pain syndrome. J Orthop Sports Phys Ther. 2005;35(12):793-801.

21. Ciena AP, Gatto R, Pacini VC, Picanço VV, Magno IMN, Loth EA. Influência da intensidade da dor sobre as respostas nas escolas unidimensionais de mensuração da dor em uma população de idosos e de adultos jovens. Semin Cienc Biol Saude. 2008; 29(2): 201-2.

22. Lequesne MG, Mery C, Samson M, Gerard P. Indexes of severity for osteoarthritis of the hip and knee. Validation--value in comparison with other assessment tests. Scand J Rheumatol Suppl. 1987;65:85-9.

23. Garzedin DD, Matos MAA, Daltro CH, Barros RM, Guimarães A. Intensidade da dor em pacientes com síndrome do ombro doloroso. Acta Ortop Bras. 2008;16(3):165-7.

24. Marx FC, Oliveira LM, Bellini CG, Ribeiro MC. Tradução e validação cultural do questionário algofuncional de Lequesne para osteoartrite de joelho e quadris para a língua portuguesa. Rev Bras Reumatol. 2006;46:253-260.

25. Fukuda TY, Ovanessian V, Cunha RA, Jacob Filho Z, Cazarini Junior C, Rienzo $F A$, et al. Pulsed short wave effect in pain and function in patients with knee osteoarthritis. J Appl Res. 2008;8(3):189-98.

26. Bandinelli S, Benvenuti E, Del Lungo I, Baccini M, Benvenuti F, Di lorio A,et al. Measuring muscular strength of the lower limbs by hand-held dynamometer: a standard protocol. Aging (Milano). 1999;11(5):287-93.

27. Bohannon RW. Hand-held compared with isokinetic dynamometry for measurement of static knee extension torque (parallel reliability of dynamometers). Clin Phys Physiol Meas. 1990;11(3):217-22.

28. Rezende MU, Gobbi RG. Tratamento medicamentoso da osteoartrose de joelho. Rev Bras Ortop. 2009;44 (1): 1-9.
29. Bjordal JM, Couppé C, Chow RT, Tunér J, Ljunggren EA. A systematic review of low level laser therapy with location-specific doses for pain from chronic joint disorders. Aust J Physiother. 2003;49(2):107-16.

30. McMeeken J, Stillman B. Perceptions of the clinical efficacy of laser therapy. Australian J Phys. 1993;39(2):101-7.

31. Navratil L, Kymplova J. Contraindications in noninvasive laser therapy: truth and fiction. J Clin Laser Med Surg. 2002;20(6):341-3.

32. Ruiz Calatrava I, Santisbetan Valenzuela JM, Gómez-Villamandos RJ, Redondo JI, Gómez-Villamandos JC, Ávila Jurado I. Histological and clinical responses of articular cartilage to low-level laser therapy: Experimental study. Lasers Med Sci. 1997;12:117-21.

33. Lin YS, Huang MH, Chai CY, Yang RC. Effects of helium-neon laser on levels of stress protein and arthritic histopathology in experimental osteoarthritis. Am J Phys Med Rehabil. 2004;83(10):758-65.

34. Jia YL, Guo ZY. Effect of low-power He-Ne laser irradiation on rabbit articular chondrocytes in vitro. Lasers Surg Med. 2004;34(4):323-8.

35. Sandoval MC, Mattiello-Rosa SM, Soares EG, Parizotto NA. Effects of laser on the synovial fluid in the inflammatory process of the knee joint of the rabbit. Photomed Laser Surg. 2009;27(1):63-9.

36. Fitzgerald GK, Axe MJ, Snyder-Mackler L. The efficacy of perturbation training in nonoperative anterior cruciate ligament rehabilitation programs for physical active individuals. Phys Ther. 2000;80(2):128-40.

37. Zacaron KAM, Dias JMD, Abreu NS, Dias RC. Nível de atividade física, dor e edema e suas relações com a disfunção muscular do joelho de idosos com osteoartrite. Rev Bras Fisiot. 2006;10 (3):279-84.

38. Brosseau L, Welch V, Wells G, Tugwell P, de Bie R, Gam A, et al. Low level laser therapy for osteoarthritis and rheumatoid arthritis: a metaanalysis. J Rheumatol. 2000;27(8):1961-9.

39. Ozdemir F, Birtane M, Kokino S. The clinical efficacy of low-power laser therapy on pain and function in cervical osteoarthritis. Clin Rheumatol. 2001;20(3):181-4.

40. World Association of Laser Therapy (WALT). Consensus agreement on the design and conduct of clinical studies with low-level laser therapy and light therapy for musculoskeletal pain and disorders. Photomed Laser Surg. 2006;24(6):761-2.

41. Bülow PM, Jensen $H$, Danneskiold-Samsøe B. Low power Ga-Al-As laser treatment of painful osteoarthritis of the knee. A double-blind placebo-controlled study. Scand J Rehabil Med. 1994;26(3):155-9.

42. Deyle GD, Henderson NE, Matekel RL, Ryder MG, Garber MB, Allison SC. Effectiveness of manual physical therapy and exercise in osteoarthritis of the knee. A randomized, controlled trial. Ann Intern Med. 2000;132(3):173-81.

43. Jamtvedt G, Dahm KT, Holm I, Flottorp S. Measuring physiotherapy performance in patients with osteoarthritis of the knee: a prospective study. BMC Health Serv Res. 2008;8:145. 